\title{
SOBRE «ALGUNOS ARGUMENTOS A FAVOR DE UNA CIENCIA JURÍDICA INTERPRETATIVA», DE ALDO SCHIAVELLO*
}

\author{
Álvaro Núñez Vaquero \\ Universidad Austral de Chile
}

RESUMEN. El presente trabajo tiene como objetivo realizar algunos comentarios críticos a un trabajo de Aldo Schiavello publicado en esta misma Revista, que constituye una defensa del modelo interpretativo de ciencia jurídica. Se comienza realizando una reconstrucción de los argumentos que ofrece SCHIAVELLO para, a continuación, analizar críticamente tres de sus tesis. La primera de ellas se refiere a la relación entre la concepción de la ciencia y el método de los estudiosos del derecho. A continuación, se analizan los argumentos que ofrece el autor en favor de la practicidad de la ciencia jurídica. Por último, se analiza el alcance de la tesis según la cual la ciencia jurídica sería una disciplina interpretativa. El texto finaliza con una crítica al modelo interpretativo de ciencia jurídica, más allá de las tesis de SchIAVELLo.

Palabras clave: Teoría de la ciencia jurídica, epistemología, método, disciplina práctica, concepto de derecho.

\section{On «Some Arguments in favor of a Interpretative Legal Science» by Aldo SCHIAVELLO}

ABSTRACT. This paper aims to make some critical remarks about Aldo SCHIAVELLO work published in this journal, which represents a defense of the interpretative model of legal science. It starts making a reconstruction of the arguments offered by SCHIAVELLO to then critically analyzing three of his thesis. The first concerns the relationship between the conception of science and the method of legal scholars. Then, the arguments offered by the author in favor of the practicality of legal science are analyzed. Finally, the scope of the thesis defending that legal science would be an interpretative discipline is analyzed. The text ends with a critique of the interpretative model of legal science, beyond the SCHIAVELLO thesis.

Keywords: Theory of legal sciences, epistemology, method, practical discipline, concept of law.

* Fecha de recepción: 21 de enero de 2015. Fecha de aceptación: 8 de abril de 2015.

Esta publicación forma parte del proyecto de investigación Fondecyt 11120311 del Programa Conicyt chileno sobre Realismo jurídico e indeterminación del derecho. Quiero agradecer a Claudio AGÜERO, Alejandro CAlzeTTA, Andrej Kristan y Matija ZGur por sus valiosos comentarios a este trabajo. Deseo agradecer también a los evaluadores anónimos de la revista Doxa por sus agudas críticas y recomendaciones. Espero haber recogido todas sus sugerencias y recomendaciones. También deseo agradecer a mis asistentes, Carla IUSPA y Paz MORA, por su atenta lectura a la última versión de este trabajo. 
- Gustavo, ¿no vas a decir nada?

- No tengo nada que decir.

- No es condición necesaria para decir algo.

Dos viejos maestros

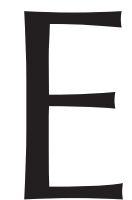

1 presente texto tiene por objeto realizar algunos comentarios críticos sobre el trabajo del profesor Aldo SCHIAVELLO «Algunos argumentos a favor de una ciencia jurídica interpretativa». Dicho trabajo tiene su origen en la ponencia que el mismo autor presentó en la Mesa redonda sobre Teoría de la Ciencia Jurídica en el XIX Seminario Latino de Teoría del derecho, organizado por la Universidad Paris X Nanterre y celebrado en la ciudad italiana de Florencia en 2013.

Para tratar de ordenar mis comentarios, comenzaré haciendo una breve exposición de las tesis defendidas por SCHIAVELLO (1). A continuación analizaré críticamente tres tesis presentadas por el autor (2-4) para finalizar con una crítica — por decirlo de algún modo- más directa, al modelo interpretativo de ciencia o dogmática jurídica (5).

\section{LA CIENCIA JURÍDICA INTERPRETATIVA}

El texto de SCHIAVELlo constituye una sólida defensa normativa de un determinado modelo de ciencia o dogmática jurídica (usaré dichas expresiones como sinónimas ${ }^{1}$ ): aquél que el propio autor llama dogmática jurídica interpretativa. La estrategia de SCHIAVELLO para defender dicha tesis parte por una descripción del modelo de ciencia jurídica analítica, que ha sido aquél que se habría consolidado en la cultura teórico-jurídica italiana. La herencia bobbiana ${ }^{2}$ sería clara en dicho modelo, el cual configura el estudio del derecho positivo como un análisis meta-lingüístico de los textos normativos, y la teoría de la ciencia jurídica como un análisis meta-meta-lingüístico (derecho—ciencia jurídica一teoría de la ciencia jurídica) ${ }^{3}$.

Según SCHIAVELLO, dicho modelo de ciencia jurídica analítica habría entrado en crisis por cambios tanto en el propio mundo como en el debate epistemológico. Si bien el autor se centra en este segundo aspecto, termina reconociendo que los desacuerdos entre empiristas y constructivistas no son tan relevantes en la práctica pues, en realidad, muy pocos constructivistas negarían el realismo metafísico y habría muy pocos empiristas (o, al menos, no deberíamos hacerles mucho caso) que nieguen que nuestro conocimiento está mediado por conceptos, categorías y teorías (SCHIAVELLO, 2014: 196-197).

Así pues, dado que las tesis neoempiristas se habrían mostrado como inadmisibles hoy en día, la manida pregunta acerca de la cientificidad habría dejado de tener sentido. Aquélla sería importante únicamente desde una perspectiva empirista radi-

\footnotetext{
1 Para un uso diferenciado de ambas expresiones me permito remitir a NúÑEZ VAQUERO, 2014.

2 Los trabajos más importantes de Norberto BoBBIO en material de ciencia jurídica han sido recopilados recientemente por Riccardo GuASTINI. Vid. BobBIO, 2011.

3 Vid. BoBBIo 2011: 1-31. Es preciso señalar, no obstante, que dicha característica —la configuración de la ciencia jurídica como un meta-discurso- que SCHIAVELLO atribuye a los autores adscritos a la corriente iusanalítica italiana es discutible (y discutida) al menos en el caso de GuASTINI. Vid. GuASTINI, 2014.
} 
cal ingenua, que debería ser, y que de hecho habría sido, abandonada (SCHIAVELLO, 2014: 201).

El problema, tanto de un determinado tipo de empirismo como de un tipo de filosofía analítica del derecho, consistiría en el monismo metodológico, esto es, la tesis según la cual para poder ser considerada científica, una disciplina debe adoptar la misma metodología que las ciencias naturales maduras. A esta tesis SCHIAVELLO opone un pluralismo metolodológico que, según el autor, sería casi unánime en la literatura, y que implicaría la dependencia del método en relación al contexto. Es más, es el propio objeto de estudio el que determinaría el método que se debe emplear para estudiarlo (SCHIAVELlO, 2014: 197, 201, 205).

En este sentido, afirma SCHIAVELLO, el derecho sería un fenómeno singular (como, en el fondo, todo fenómeno estudiado por las ciencias sociales) en la medida en que está compuesto por hechos humanos, y el conocimiento de aquéllos no puede ser de carácter neutral, avalorativo ni impermeable, siendo así poca la distancia entre sujeto y objeto de estudio. De este modo, sujeto cognitivo y objeto se influirían mutuamente, configurando el propio estudioso el objeto de estudio «derecho». Ello explicaría, entre otras cosas, los desacuerdos acerca de qué es el derecho, lo que, a su vez, lleva a pensar que aquél de «derecho» sería un concepto interpretativo (SCHIAVELLO, 2014: 197).

Esta recíproca influencia entre objeto de estudio y sujeto cognitivo se convertiría en sinergia desde el momento en que el derecho cumple la función de orientar la conducta, por lo que la ciencia jurídica no podría no reflejar dicha propiedad. La ciencia jurídica debe, pues, adoptar el punto de vista del participante, es decir, de quien adopta el derecho como criterio para calificar comportamientos (SCHIAVELLO, 2014: 198 y ss.).

Ahora bien, el argumento primordial de SCHIAVELLO, antes que de carácter teórico o conceptual, es de carácter normativo: la ciencia jurídica debe ser una disciplina práctica. En caso contrario, una de dos: bien se trata de una disciplina completamente irrelevante, bien de una disciplina ideológica (en el sentido de introducir juicios valorativos bajo la apariencia de ser meramente descriptivos) (SCHIAVELLO, 2014: 199 y 209).

No obstante, ello no significa, según SCHIAVELLO, que la ciencia jurídica interpretativa sea la única aproximación legítima en ciencia jurídica. Junto a ella podemos encontrar otras aproximaciones «externas» que no adoptan el punto de vista del participante, y que más se acercan a la hermenéutica de la sospecha (TRASíMACO, MARX, FOUCAULT, LUNDSTEDT y FRANK son los ejemplos que SCHIAVELLO refiere). Sin embargo, estas últimas tienen (y deben tener) un carácter secundario en la medida en que, por un lado, son parasitarias respecto de la aproximación basada en el punto de vista del participante y, por el otro, y sobre todo, porque si la ciencia jurídica adoptase un punto de vista externo la propia existencia del derecho correría peligro. Es decir, sin una ciencia jurídica que adopte el punto de vista interno de la práctica jurídica, el derecho como tal estaría en riesgo de muerte (SCHIAVELLO, 2014: 200).

A continuación, SCHIAVELLO defiende la idea según la cual aquél de ciencia jurídica - y no sólo el de derecho- sería un concepto interpretativo. El autor presenta de manera clara y sistemática cuáles son las características de los conceptos interpretativos, una suerte de reformulación de la noción de concepto esencialmente controvertido de Gallie (SCHIAVELlo, 2014: 203-205). 
Desde este punto de vista, si el concepto de «derecho» es esencialmente controvertido, y la ciencia jurídica refleja (o debe reflejar) el carácter del derecho, entonces aquél de «ciencia jurídica» también sería, o debería ser, un concepto interpretativo. Ahora bien, dentro de las diferentes interpretaciones que admitiría la ciencia jurídica la mejor sería una versión asimismo interpretativa. En particular, SCHIAVELLO defiende un modelo que coloque como valor fundamental la integridad tal y como la entendía Ronald DwORKIN (SCHIAVELLO, 2014: 205 y ss.).

SCHIAVELLO finaliza su trabajo recogiendo una clasificación de dos grandes modelos de ciencia jurídica enunciada por Norberto BOBBIO: aquél del guardián y aquél del creador de derecho (BOBBIO, 2007). A la luz de factores institucionales, sociales y culturales se podría explicar, según el autor, el triunfo del modelo creador de derecho, poniendo definitivamente en jaque al modelo descriptivista de ciencia jurídica, propio de la tradición iusanalítica italiana, que mira desde afuera al derecho, al menos en alguna de sus versiones (SCHIAVELLO, 2014: 211 y ss.).

Estos son, al menos eso espero ${ }^{4}$, los principales argumentos del trabajo de SCHIAVELLO. Son muchas las ideas del trabajo que merecen la pena ser comentadas y discutidas. Sin embargo, aquí me voy a limitar a analizar tres tesis de SCHIAVELLO que constituyen, creo, el centro de su argumentación. Además de porque estas tres tesis son de por sí interesantes, me concentraré en estos puntos porque constituyen la versión dominante de lo que sería, o debería ser según muchos autores, la ciencia jurídica hoy. En primer lugar, analizaré la pertinencia de seguir hablando sobre la cientificidad de la ciencia jurídica (2); en segundo lugar, analizaré la cuestión de si la ciencia jurídica es, o debe ser, una disciplina práctica (3); en tercer lugar, me preguntaré si aquél de ciencia jurídica es un concepto interpretativo (4). Finalizaré con una crítica que no analiza directamente los argumentos expuestos por SCHIAVELLO pero que intenta poner en cuestión el núcleo de la dogmática interpretativa.

\section{CIENTIFICIDAD, MÉTODO Y OBJETO DE ESTUDIO}

La primera tesis que es preciso analizar tiene que ver con el nexo que SCHIAVELLO establece entre el método de la dogmática jurídica, el objeto de estudio y la cientificidad. Su tesis, en este sentido, parece clara: «La posibilidad de cualificar como "científico" un ámbito de conocimiento no pasa por la adopción de un método determinado, en particular el método de las ciencias empíricas maduras. La idea, banal, es que el método depende del contexto o, en otras palabras, que es el ámbito de experiencia del objeto de estudio el que determina cuál sea el método adecuado que se tiene que adoptar [siendo] el problema de la cientificidad de la dogmática [...] "más verbal que real"» (SCHIAVELLO, 2014: 197, 201).

La anterior afirmación puede ser, no obstante, descompuesta en tres diferentes tesis, las cuales merecen consideración separadamente. En primer lugar, la tesis según

${ }^{4}$ Albergo ciertas dudas sobre si he comprendido correctamente todas y cada una de las tesis de SCHIAVELLO. La claridad o falta de claridad de las tesis de SCHIAVELLO ha sido también objeto de controversia con los evaluadores de este trabajo. 
la cual carece de sentido seguir preguntándose por la cientificidad de la ciencia jurídica. En segundo lugar, aquélla según la cual la posibilidad de calificar como científica a una disciplina no depende de que aquélla adopte el mismo método que las ciencias empíricas maduras. Por último, la idea de que el método depende del objeto de estudio ${ }^{5}$.

En este apartado analizaré únicamente las dos primeras tesis. En particular, me centraré en la relevancia de la propia cuestión de la cientificidad y, en segundo lugar, en la posible conexión entre cientificidad y método de las ciencias empíricas maduras. Dejaré la cuestión sobre la relación entre método y objeto de estudio para la cuarta sección (infra, 4.2).

\subsection{La cuestión de la cientificidad}

Lo primero que hay que hacer es analizar brevemente la tesis según la cual sería irrelevante discutir o determinar si la dogmática jurídica es una disciplina científica. SCHIAVELlo sostiene la idea, de bobbiana memoria ${ }^{6}$, según la cual la cuestión de la cientificidad de la dogmática es poco interesante o puramente escolástica. Pues bien, si se tratara únicamente de una cuestión teórica o académica, aquélla sería completamente irrelevante. El problema es precisamente que la cuestión no es, a un análisis más detenido, de ningún modo irrelevante. Por «relevancia»o «relevante» aquí entiendo sencillamente aquella propiedad que se puede predicar de una información que, de ser conocida por un agente racional, es considerada como una razón para la acción. Es decir, que lleva a un agente racional a modificar su comportamiento con base en ella o, al menos, le obliga a reconsiderar su acción.

Si bien han sido muchos y muy diferentes los conceptos o criterios para calificar como científica a una disciplina, lo cierto es que siempre se ha atribuido un mayor valor a las disciplinas que han sido calificadas como científicas. Por ello, algunos autores como NINO (NINO, 2003: 13) han sugerido abandonar completamente la cuestión debido a la carga emotiva positiva que lleva consigo el término «ciencia».

5 Me doy cuenta de que la afirmación según la cual, para SCHIAVELLO, el método de la ciencia depende de propiedades de su objeto de estudio puede ser discutible con base en la cita del párrafo anterior. Sin embargo, creo que hay algunos otros pasajes del texto que permiten imputar al autor dicha tesis: «[L]a idea de que el derecho sea interpretación y que la ciencia del derecho se resienta de esta característica de su objeto se ha convertido en un tópico» (SCHIAVELLO, 2014: 195); «Si aceptamos la tesis de que el objeto de estudio influye sobre el método científico, entonces un discurso sobre la ciencia jurídica - y una defensa de una ciencia jurídica «interpretativa»-impone la realización de una breve reflexión preliminar sobre el objeto de la ciencia jurídicas, es decir, sobre el derecho» (SCHIAVELLO, 2014: 197); «A fin de determinar cuáles sean las características de una ciencia jurídica interpretativa es útil retomar y profundizar en las reflexiones precedentes sobre la influencia que el objeto de estudio - el derecho, en nuestro caso- y las características específicas tienen en la actividad cognoscitiva. La naturaleza interpretativa de la ciencia jurídica depende de hecho de las características del concepto de derecho» (SCHIAVELLO, 2014: 205).

En cualquier caso, me parece que si se sostiene, por un lado, que el derecho es una práctica social interpretativa y, por el otro, que el método depende del objeto de estudio, entonces podemos concluir que si se defiende que el objeto de estudio viene determinado por el ámbito de experiencia del objeto de estudio, se está afirmando que el objeto de estudio determina el método. Espero, en cualquier caso, no estar malinterpretando las tesis de SCHIAVELLO. Agradezco a Claudio AGÜERO por haberme obligado a precisar esta tesis.

${ }^{6}$ Bоввіо, 1997: 134. 
Sin embargo, pese a su indudable carga emotiva positiva, ello no significa que la calificación como científicas de determinadas disciplinas haya sido un simple capricho de la historia del conocimiento humano. Antes bien, cuando se ha calificado como científica una determinada disciplina ha sido porque se ha considerado aquélla, más allá de los errores que se hayan producido, como más fiable.

En realidad, la cuestión no parece de ningún modo irrelevante ni en términos generales ni para la dogmática jurídica en particular. En términos generales, porque la calificación de una determinada disciplina como científica ha sido como una especie de sello de calidad que permite a los no expertos establecer qué valor pueden atribuir al conocimiento generado por las disciplinas así calificadas, es decir, cuánto se puede confiar en aquéllas.

Ahora bien, ¿por qué se ha considerado, o deberíamos considerar, más fiables a las disciplinas científicas? La razón es que aquéllas permiten llevar a cabo actividades que no podrían ser realizadas sin tal conocimiento: construir aviones, prevenir enfermedades, usar ordenadores, etc. Es decir, las disciplinas científicas nos ofrecen el conocimiento necesario para llevar a cabo actividades como las mencionadas, permitiéndonos hacer predicciones acerca de las consecuencias de nuestras acciones, de los cambios que sufrirá el mundo, y de cómo nos afectarán ${ }^{7}$. Volveré enseguida sobre este punto (infra 2.2).

Más allá de la respuesta, la pregunta sobre la cientificidad parece relevante también para la dogmática jurídica: ¿cuánto nos podemos fiar de que las tesis de la dogmática reflejan el contenido del derecho? ¿Cuánto podemos confiar en que los jueces decidirán tal y como cree la dogmática que deberían de hacerlo? ¿Tiene algún poder explicativo la dogmática como instrumento para prever las consecuencias de mis acciones, orientándolas de este modo? ¿Sirve la dogmática jurídica a quienes practican el derecho como abogados para orientar su acción? ¿Puede acaso un juez confiar en que la respuesta que debe adoptar es la que le indica la dogmática? Determinar el valor científico de la dogmática jurídica permite establecer a los no dogmáticos —abogados, jueces, ciudadanos, legislador, etc.- en qué medida pueden confiar en las afirmaciones que realizan los dogmáticos sobre el derecho ${ }^{8}$. Así que la cuestión de la cientificidad parece estar bien lejos de ser una cuestión irrelevante?

7 Por ejemplo, yo no sé si hay que vacunar a los niños pequeños, ni estoy en disposición de averiguarlo por mi cuenta. Ahora bien, supongo que me puedo fiar más de los estudios de la pediatría convencional que de las afirmaciones de un curandero.

${ }^{8}$ La consideración científica o no de la dogmática parece ser relevante en múltiples campos como, por ejemplo, para la enseñanza del derecho. En efecto, parece que la configuración actual de la educación jurídica, basada todavía hoy sustancialmente en la transmisión de conocimientos, está fundada en la idea de que tal tipo de información —aquélla sobre la que son interrogados los estudiantes- tiene algún tipo de valor científico. Pero si no es así, como piensan muchos, entonces ello debería llevar a una profunda revisión de los programas de estudio, ya que los contenidos sobre los que se evalúa a los estudiantes únicamente serían opiniones más o menos elaboradas acerca del contenido del derecho. En el mejor de los casos, se estaría evaluando a los estudiantes sobre el dominio de meta-descripciones (no científicas de por sí) de las opiniones de determinados juristas. Pero, si tales opiniones no revisten valor científico (ni tampoco su meta-descripción), ¿para qué pedir a los estudiantes que las aprendan y memoricen?

9 Lo sería, tal vez, y sólo en cierto sentido, si fuera imposible crear una ciencia jurídica realmente científica, pero eso es una cuestión abierta que se discutirá más adelante. Vid. infra 3.2. 


\subsection{La relación entre método de las ciencias empíricas maduras y cientificidad}

Volvamos a la tesis de SCHIAVELLO: «La posibilidad de cualificar como «científico» un ámbito del conocimiento no pasa por la adopción de un método determinado, en particular el método de las ciencias empíricas maduras» (SCHIAVELLO, 2014: 197). SCHIAVELLO, por tanto, estaría rechazando la tesis —imputada a los neo-empiristas (y, sospecho, a los realistas genoveses antes que al iuspositivismo jurídico italiano) ${ }^{10}$ según la cual para ser científica una disciplina debe adoptar el mismo método que las ciencias empíricas maduras.

Me parece que atribuir a los neoempiristas la anterior afirmación incurre en un error que, si bien es bastante común en la discusión teórico-jurídica, no es por ello menos pernicioso. En efecto, resulta francamente extraño sostener que las ciencias sociales deben adoptar el mismo método que las ciencias empíricas maduras. Se trata, me parece, de una falacia del hombre de paja: nadie ha pensado nunca seriamente en utilizar los métodos de las ciencias empíricas maduras para determinar el contenido del derecho.

La anterior tesis, convertida por SCHIAVELLO en objeto de crítica, se basa en una falta de distinción entre dos aspectos implicados en aquélla: entre los planos metodológico y epistemológico. Por «metodología» podemos entender aquel discurso que trata de elaborar herramientas que sirvan para obtener enunciados base (enunciados descriptivos sobre) de un determinado objeto de estudio, afinar y evaluar tales instrumentos, y derivar conclusiones a partir de aquéllos. Por «epistemología», por el contrario, podemos entender aquel discurso que pretende establecer qué es posible conocer y cuándo estamos frente a conocimiento justificado. Se trata, desde luego, de planos entre los que existe una conexión pero que pueden, y deben, ser distinguidos.

Desde el primer punto de vista, el metodológico, es completamente implausible sostener la unidad de las disciplinas científicas. Ni siquiera parece posible predicar dicha tesis para el ámbito de las ciencias empíricas maduras: nadie pretende realizar un estudio sobre la transmisión de la antimateria utilizando los métodos de la química orgánica, o hacer física cuántica con la metodología de la biología. En realidad, dentro de las ciencias empíricas maduras conviven una buena cantidad de métodos diferentes y, en ocasiones, alternativos. Lo mismo ocurre, pero en mayor medida, en las disciplinas sociales. Por ejemplo, si lo que nos interesa es saber cómo se comportan o piensan nuestros representantes políticos se pueden utilizar diferentes métodos: encuestas, entrevistas, análisis de declaraciones de actividades, análisis de discursos políticos, análisis de redes, etc. La unidad de la ciencia, entendida como tesis metodológica, simplemente carece de sentido.

Ahora bien, si así están las cosas, entonces el hecho de que una determinada disciplina asuma un determinado método no es condición suficiente para considerarla como científica. Desde luego, se puede afirmar que para que una disciplina sea considerada científica es preciso que su metodología satisfaga algunos requisitos como, por ejemplo, que sus mediciones o enunciados base no dependan de las propias preferencias o

10 Esto se debe a que, como el propio SCHIAVELLO reconoce, sus tesis han sido en parte avanzadas por Mario JORI y Uberto SCARPELLI, quienes ya fueron críticos con el realismo jurídico genovés. 
impresiones del investigador ${ }^{11}$. Sin embargo, en las ciencias modernas, también en las sociales, disponemos de métodos alternativos que satisfacen criterios como el anterior. Así pues, si hay diferentes métodos que satisfacen estándares mínimos de cientificidad, entonces no podemos afirmar que la cientificidad dependa exclusivamente del método de estudio empleado.

Desde donde es posible, y plausible, por el contrario, sostener la unidad de las disciplinas científicas es desde el punto de vista epistemológico. A saber: no desde el punto de vista de cuáles son las actividades que es preciso llevar a cabo para conocer un objeto (metodología), sino desde el punto de vista de qué es lo que podemos conocer o cuándo estamos frente a conocimiento justificado. Un discurso, dicho de otro modo, que nos permita distinguir entre disciplinas científicas y no científicas, y que permita reorientar una disciplina para convertirla en científica.

A lo largo de la historia de la filosofía de la ciencia se han ofrecido diferentes criterios sobre cuándo una disciplina puede ser considerada científica. En una apretadísima y reductiva síntesis se podría afirmar, con BOBВIO (BОВBIO, 2011, 11 y ss.), que las concepciones dominantes de la ciencia han sido fundamentalmente dos: según la primera, una disciplina sería científica en la medida en que está compuesta por un conjunto de enunciados descriptivos sintéticos verdaderos (concepción empirista); según la segun$\mathrm{da}$, una disciplina científica sería una disciplina rigurosa, constituida por un conjunto de enunciados ordenados, en el que existen una serie de tesis primarias u originarias, un conjunto de reglas de transformación, y una serie de tesis derivadas producto de la combinación de las dos anteriores (concepción racionalista).

Sin embargo, hay buenas razones para descartar aproximaciones externas o filosóficas como las dos anteriores en epistemología, es decir, a la hora de establecer qué es o cuándo estamos frente a una disciplina científica. La más importante de ellas es que parece que debemos rechazar las justificaciones fundacionalistas de nuestro conocimiento: no somos capaces de encontrar una justificación externa acerca de cuándo estamos frente a conocimiento verdadero. Es decir, no disponemos de instrumentos para asegurar que el conocimiento de las disciplinas científicas —entendidas en alguno de los sentidos anteriores - sea un conocimiento verdadero (o que realmente refleje la realidad).

Ahora bien, si consideramos que tenemos ciertas disciplinas que gozan de mayor prestigio porque tienen una mayor capacidad explicativa (entendida como capacidad predictiva), la opción que parece más plausible es fijarnos en aquéllas para determinar qué debemos entender por ciencia: debemos, dicho de otro modo, naturalizar la epis-

11 No es posible ni siquiera hacer un breve resumen de las tesis en relación a cómo debe ser una metodología para poder ser considerada científica, debido a que requeriría un espacio superior del que aquí se dispone. Pero, además, este no es el aspecto que me interesa destacar. Ello debido a que voy a sostener que lo que debería ser considerado determinante a la hora de calificar como científica una disciplina es que consiga (o, al menos, intente conseguir) resultados similares a aquéllos de las disciplinas científicas más exitosas: aquéllas que son presupuestas por las tecnologías, precisamente por tener una gran capacidad predictiva. En este sentido, parece existir una relación no conceptual sino causal entre la metodología elegida y el tipo de resultados que se pretende alcanzar. Si bien podría suceder que una disciplina cuyo método (mejor dicho, su aplicación) dependa de las impresiones subjetivas de sus investigadores alcance resultados exitosos, resulta extraño imaginar cómo una disciplina cuyos instrumentos metodológicos estén, por ejemplo, centrados en las apreciaciones subjetivas del investigador, pueda llegar a tener éxito. 
temología. Ello porque, parafraseando a CARNAP, no es posible bajarnos de la barca del conocimiento para evaluar la propia barca, sino que únicamente nos podemos colocar en la parte que parece más sólida — la de las disciplinas más exitosas - para evaluar y tratar de mejorar el resto de la embarcación. Es decir, ante la imposibilidad de justificar en última instancia nuestro conocimiento en una base sólida, la mejor opción parece revisar nuestra epistemología a la luz del que parece nuestro conocimiento más fiable: el conocimiento de las disciplinas más exitosas.

Así las cosas, es preciso averiguar cuáles de las características de las disciplinas que consideramos más exitosas harían que una disciplina se convierta en científica. Aquí las alternativas son fundamentalmente dos: bien nos fijamos en un método común a las disciplinas más exitosas, bien nos fijamos en el tipo de resultados que alcanzan dichas disciplinas. Como ya se ha dicho, la multiplicidad y variedad de métodos empleados por las disciplinas exitosas hace poco recomendable reconducir todas ellas a un mismo método, por lo que la alternativa más plausible parece encontrarse en el tipo de resultados que alcanzan las disciplinas más prestigiosas. Por tanto, para calificar una disciplina como científica aquélla debe alcanzar (o intentar alcanzar) resultados similares a los disciplinas más exitosas.

Podría, no obstante, pensarse que se trata de dos criterios de cientificidad diferentes: la capacidad predictiva y la capacidad para modificar el mundo ${ }^{12}$. Se trata, sin embargo, de un mismo criterio observado desde dos puntos de vista diferentes: si nos podemos fiar más de las disciplinas científicas es por el tipo de resultados que alcanzan (o, al menos, que intentan alcanzar), esto es, por su capacidad de realizar predicciones sobre hechos o eventos futuros. Dicho de otro modo: las disciplinas que han gozado y gozan de mayor reconocimiento social disfrutan de aquél porque son aquéllas que permiten realizar un mayor número de actividades prácticas, pero dichas actividades prácticas pueden ser llevadas a cabo precisamente porque dichas actividades - la construcción de aviones o la creación de vacunas- presuponen disciplinas con una fuerte capacidad predictiva.

Desde el anterior punto de vista, parece posible seguir planteando la tesis de la unidad del conocimiento científico como una cuestión epistemológica relativa al tipo de resultados que pretenden alcanzar tales disciplinas, pero no como una cuestión relativa al método de las disciplinas. De este modo, afirmar que la dogmática jurídica debe ser una disciplina científica no implica necesariamente que aquélla deba adoptar el mismo método que las disciplinas científicas maduras, pero sí que debe intentar alcanzar resultados similares: generar explicaciones con capacidad predictiva. Con ello no quiero decir todavía que la ciencia jurídica deba ser una disciplina científica —eso es otra cuestión - pero sí que no se trata de una cuestión irrelevante, y que si fuera recomendable que fuese científica, ello no implicaría adoptar los métodos de las ciencias empíricas maduras, sino sólo que tal ciencia jurídica intente realizar predicciones sobre comportamientos futuros.

No obstante, desde un punto de vista diferente, podría argumentarse que, si las disciplinas científicas se caracterizan por ser útiles para llevar a cabo actividades prácti-

12 Esta ambigüedad me fue señalada por ambos evaluadores de este trabajo. 
cas, entonces la dogmática interpretativa que defiende SCHIAVELLO sería una candidata ideal para formar parte de las disciplinas científicas. Ello porque, se podría sostener, la dogmática jurídica sirve para producir cambios en el derecho y, de consecuencia, en la sociedad ${ }^{13}$.

Existen, sin embargo, todavía algunas buenas razones para no considerar a la dogmática jurídica así entendida como una disciplina de carácter científico desde este punto de vista. Para entender la primera razón es preciso, en primer lugar, aclarar la relación entre conocimiento científico y conocimiento técnico. He sostenido que el conocimiento científico es aquél que permite llevar a cabo actividades prácticas que si careciéramos de tal conocimiento sería imposible realizar, justamente porque este conocimiento tiene una importante fuerza predictiva (o, al menos, intenta tenerlo). El conocimiento científico es, por tanto, aquel conocimiento que presuponemos para llevar a cabo actividades de tipo técnico como construir aviones o generar vacunas ${ }^{14}$. Ahora bien, el conocimiento técnico de un ingeniero aeronáutico no debe ser confundido con el conocimiento científico del estudioso de física, el cual es presupuesto por quien diseña aviones ${ }^{15}$ : una cosa es saber qué materiales debo utilizar para el fuselaje de un avión, y otra las leyes de la física sobre la presión.

Pues bien, la dogmática jurídica es considerada, por quienes defienden un modelo interpretativo, como una disciplina práctica. Creo que, sin entrar en demasiadas disquisiciones, por «disciplina práctica» podemos entender aquélla que no pretende responder a la pregunta sobre cómo es el mundo sino a aquélla sobre cómo debe ser (o qué debemos hacer). Ello, además, en un sentido no meramente técnico o instrumental sino de carácter normativo en sentido fuerte; es decir, no sólo cuáles son los medios idóneos para alcanzar un determinado fin, sino cuáles son los fines que hay que perseguir. En este sentido, se podría descartar la idea de que la dogmática interpretativa sea una ciencia, justamente por ser una disciplina práctica que no genera conocimiento disponible para otra disciplina, ya que ella misma, suele sostenerse ${ }^{16}$, es un conocimiento aplicado (más parecido, por tanto, a la pintura que a la biología) ${ }^{17}$.

13 Abordo esta tesis precisamente porque me fue sugerida por uno de los evaluadores anónimos de este trabajo. Aquél consideraba que la noción de cientificidad que utilizo es contradictoria, aportando como prueba o indicio precisamente este argumento.

14 Vid. BROnCANo, 2000, 91. Desde un punto de vista pragmatista, se podría afirmar que la única forma de probar que estamos frente a conocimiento científico es si podemos aplicar aquél en alguna tarea práctica. No se trata de sustituir la noción de verdad por aquella de confirmación, sino que la mejor forma de probar la verdad de una teoría científica sería, desde este punto de vista, que aquélla sea confirmada por su empleo en la construcción de un artefacto técnico que funciona. Si tenemos en cuenta la imposibilidad de resolver el problema de la inducción, aquél del funcionamiento práctico parece un excelente criterio de confirmación. No obstante, no se puede garantizar desde este punto de vista que el funcionamiento del artefacto no está basado en una casualidad en lugar de en una relación causal.

15 BRonCANO, 2000, 86 y ss.

16 Vid. Ruiz Miguel, 2012, y AtienZa, 2014.

17 Existen, en este sentido, al menos dos importantes diferencias entre las disciplinas técnicas (o tecnológicas) como la aeronáutica o la medicina y la dogmática jurídica interpretativa. La primera de ellas consiste en que, mientras que nadie pone en cuestión cuándo una propuesta técnica tiene éxito — cuando el avión vuela o cuando la persona se cura - porque disponemos de criterios compartidos para determinar el éxito en tales disciplinas, ocurre precisamente lo contrario cuando hablamos de la dogmática jurídica. ¿Cuándo estamos frente a una buena construcción dogmática? ¿Cuando resulta persuasiva? ¿Cuando alcanza la respuesta correcta? ¿Cuando está bien justificada? En tal sentido, la dogmática se parece más a la cocina que a la medicina, puesto que el éxito de una propuesta dogmática no depende de criterios objetivos sino de preferencias subjetivas. 
Cabría, no obstante, preguntarse si la dogmática puede ser considerada como un conocimiento necesario para quien pretende cambiar el derecho y/o la sociedad y, en este sentido, indirectamente como una disciplina científica. No obstante, también debemos descartar esta idea, por dos razones ulteriores.

En primer lugar, si lo que pretendemos es cambiar el derecho, para lograr tal objetivo, antes que recurrir a la dogmática interpretativa, lo que debemos es informarnos acerca de cuáles son los medios idóneos para influir en las opiniones de los legisladores y/o de quienes aplican el derecho, esto es, de quienes cambian el derecho. La dogmática interpretativa no constituye un conocimiento necesario para cambiar el derecho, sino que nos dice en qué sentido debe ser modificado aquél. Ello salvo que admitamos que siempre triunfa la solución correcta (lo que parece una ingenuidad).

En segundo lugar, si lo que pretendemos es cambiar la sociedad a través del derecho, tampoco la dogmática interpretativa resulta de demasiada utilidad. Es decir, si lo que pretendemos es determinar cómo o en qué manera debemos modificar el derecho para producir cambios sociales, la dogmática interpretativa tampoco es una disciplina relevante. La razón es que para modificar la sociedad no basta con establecer cuál es la respuesta correcta jurídicamente (que sería, me parece, el objetivo de la dogmática interpretativa), sino que tenemos que conocer cuáles son los mecanismos sociales que hacen que las personas modifiquen su comportamiento, y cómo ello permite generar cambios en toda la sociedad. Desde luego, hay disciplinas jurídicas como la sociología del derecho, el análisis económico del derecho (al menos, una determinada forma de cultivar este último) o un análisis de tipo instrumentalista como el que alguna vez sugirió Summers (Summers, 1971), que sí constituyen un conocimiento necesario para cambiar la sociedad. Ahora bien, la dogmática interpretativa no analiza cuáles son los factores que motivan el comportamiento humano, lo que parece condición necesaria para intentar modificar la sociedad. La dogmática interpretativa tampoco parece ser pues una disciplina científica en este sentido.

\section{LA PRACTICIDAD DE LA CIENCIA JURÍDICA}

La segunda idea de SCHIAVELLO que quiero comentar se refiere a la practicidad —o, si se prefiere, a la normatividad de la ciencia jurídica, en uno de sus posibles significados- de la dogmática jurídica. En una línea similar a sus anteriores argumentos, SCHIAVELLO defiende la existencia de un vínculo entre el carácter práctico del propio derecho, y el carácter práctico de la dogmática jurídica. Dicho sintéticamente: si el

La segunda diferencia entre disciplinas como la dogmática y las ingenierías es que, como apuntó en su momento ATIENZA (ATIENZA, 1986), las tecnologías como la medicina o la aeronáutica presuponen conocimientos científicos mientras que las técnicas no. En este sentido, cabría preguntarse genuinamente si la dogmática jurídica presupone algún tipo de conocimiento científico, aunque prima facie no parece que se pueda identificar ninguno.

No obstante, se trata de dos criterios diferentes, siendo posible que haya disciplinas que presupongan conocimientos científicos pero en las que no existe un criterio claro de éxito, pero también al contrario. Piénsese, por ejemplo, en la arquitectura que presupone conocimiento científico pero cuyas condiciones de éxito no son claras; o, al contrario, la técnica de construir barricas o cubas, que no presupone conocimiento científico pero cuyas condiciones de éxito parecen claras. He defendido tesis similares en NúÑEZ VAQUERO, 2014. 
derecho es un instrumento de carácter práctico para motivar la conducta que ofrece razones para la acción, entonces la ciencia jurídica debe ser una disciplina práctica (SCHIAVELLO, 2014: 199).

SCHIAVELLO nos ofrece dos argumentos para justificar la tesis según la cual la ciencia jurídica es y/o debe ser una disciplina de carácter práctico. El primero de ellos es de carácter teórico y afirma que la ciencia jurídica debe ser práctica porque tiene que dar cuenta del punto de vista de los participantes (SCHIAVELLO, 2014: 198). En segundo lugar, aporta un argumento de carácter normativo según el cual una ciencia jurídica no práctica sería irrelevante y/o ideológica (SCHIAVELLO, 2014: 199). Analicemos cada uno de ellos separadamente.

\subsection{El argumento teórico}

El primer argumento es de carácter teórico: la dogmática jurídica (SCHIAVELLO, 2014: 198), no puede no ser una disciplina práctica porque tiene que dar cuenta del punto de vista interno de la práctica jurídica.

En efecto, parece plausible afirmar que no es posible determinar el contenido del derecho (objetivo de la dogmática jurídica, según SCHIAVELLO, 2014: 201), sin tener mínimamente en cuenta las creencias de los participantes. Ahora bien, prácticamente nadie ha prescindido completamente del punto de vista interno de los participantes: ni siquiera Jerome FRANK, y menos aún Vilhelm LUNDSTEDT ${ }^{18}$, como sugiere SCHIAVELLO (SCHIAVELLO, 2014: 200). Lo que sucede es que no sólo hay diferentes grados de compromiso o de punto de vista interno, como afirma SCHIAVELlo (ScHiavello, 2014: 198), sino que también existen diferentes formas en las que se puede dar cuenta de dicho punto de vista interno.

Supongo que la teoría jurídica ha discutido tanto esta cuestión que no merece la pena detenerse demasiado en ella ${ }^{19}$. No obstante, debo confesar que me sigue pareciendo igualmente extraño negar que del mismo modo que podemos dar cuenta de qué es un partido de fútbol sin correr en calzones cortos por un campo o ser hincha ${ }^{20}$, tam-

18 Merece la pena señalar que esta fue precisamente la estrategia o el principal objeto de estudio de autores como Vilhelm LUNDSTEDT o Jerome FRANK. En efecto, el realismo de ambos proviene precisamente de la constatación de que lo más importante cuando se estudia el derecho es precisamente el punto de vista interno de los juristas. Sin embargo, dicho punto de vista interno era bien sumamente indeterminado (para FRANK) (FRANK, 2009), bien directamente pernicioso (para LUNDSTEDT) (LUNDSTEDT, 2014), por lo que resultaba necesario no adoptarlo en primera persona, sino describirlo en tercera persona. Antes que ignorar el punto de vista interno del derecho, estos estudiosos dedicaron todas sus investigaciones a aquél.

19 Me limito a citar uno de los artículos más relevantes sobre la cuestión: BuLYGIN, 1991.

20 Uno de los evaluadores de este trabajo calificó esta analogía como falsa. Sin embargo, me cuesta imaginar en qué sentido dicha analogía sería falsa (a menos que se considere que no hay de hecho ninguna similitud entre ambas prácticas, lo que no creo que sea el caso). Creo, por el contrario, que se trata de una analogía plausible en la medida en que se trata de prácticas en las que los participantes muestran un alto grado de compromiso. Si sigue sin parecer plausible la analogía, se pueden utilizar otras: ¿es acaso necesario creer en Dios para dar cuenta de la práctica religiosa, o para saber que la doctrina de la Iglesia católica condena el aborto o el suicidio?

Se podría afirmar, por otro lado, que lo que podemos conocer de este modo son sólo los casos fáciles. No obstante, los casos fáciles, según el otro evaluador, serían sólo la cristalización de la solución de un caso difícil. Por tanto, el tipo de conocimiento necesario para conocer los casos difíciles tendría (algún tipo de) preferencia sobre el método para conocer los casos fáciles. Sin embargo, esta tesis, según la cual para conocer la solución 
bién es posible dar cuenta del contenido del derecho sin participar de él ni sentirnos comprometidos de ningún modo con su bondad u obligatoriedad. ¿Es necesario haber sido víctima del terrorismo para entender aquél? ¿Hace falta participar o ser víctima de la mafia para saber en qué consiste? Creo que negar esto nos lleva a conclusiones contraintuitivas, como que tengamos que dejar de hablar de todo aquello de lo que no participamos comprometida y activamente en primera persona.

No se trata, claro está, de ignorar que hay participantes ni de limitarse a constatar que existen sujetos que adoptan la posición del participante, como SCHIAVELLO parece imputar a todos los autores que no adoptan el punto de vista del participante en primera persona (SCHIAVELLO, 2014: 198). Antes bien, la alternativa consiste en explicar y tener en cuenta cómo razonan y cuáles son las creencias de los participantes, sin por ello dar por buena su descripción o comprensión sobre que están haciendo tales participantes, sobre qué es el derecho o sobre su contenido ${ }^{21}$.

Por supuesto, alguien nos podrá decir que la descripción sobre el contenido del derecho de un no participante no es igual de buena que la explicación de un participante, de alguien que se siente comprometido con la práctica. Sin embargo, ello va a depender de qué consideremos una buena exposición de cuál es el contenido del derecho. Si bien se pueden dar amplias y sofisticadas respuestas, lo cierto es que no parece que se pueda dar una de carácter definitivo, al menos desde la teoría, a este último interrogante: ¿es mejor una descripción del contenido del derecho basada sólo en reglas que una que incorpore el uso de principios? ¿No será mejor describir sencillamente que soluciones derivan los jueces de los materiales normativos?

Preguntas como estas no tienen respuesta desde el punto de vista teórico, sino que, como nota el propio SCHIAVELlo (SCHIAVELLO, 2014: 211), se trata de preguntas prácticas. ¿Cuáles son los objetivos de investigación que consideramos valioso perseguir? ¿Para qué queremos una dogmática jurídica? ${ }^{22}$. Ahora bien, del hecho de que sea una

de los casos difíciles es preciso adoptar en primera persona el punto de vista del participante, presupone que en los casos difíciles ya hay una respuesta correcta. Sin embargo, más bien parece que la respuesta al caso difícil debe ser creada o, si se prefiere, construida. Lo que desde un punto de vista no interno se puede hacer en estas situaciones es dar cuenta de que no hay todavía solución, sino varias propuestas de solución en conflicto. Es más, se pueden también ensayar o sugerir hipótesis sobre posibles respuestas, pero no por ello es necesario comprometerse con ninguna de ellas.

21 Tampoco el argumento de la mayor distancia entre sujeto y objeto de estudio en las ciencias empíricas parece demasiado plausible. Para darse cuenta de ello basta con percatarse de que los científicos de las disciplinas maduras son muy conscientes de que trabajan en condiciones ideales y que, cuando no lo hacen, su observación puede modificar el objeto de estudio (como sucede, por ejemplo, en la zoología).

22 Se trata, nótese, de una pregunta diferente a si es mejor un derecho compuesto exclusivamente por reglas o por reglas y principios, o cualquier otra similar acerca de cómo debe ser el derecho. La pregunta aquí es también práctica, pero diferente: ¿qué tipo de investigación es deseable que lleven a cabo los estudiosos del derecho? Hay que señalar que no habría contradicción alguna en decir que preferimos un derecho compuesto eminentemente por principios pero que, para garantizar un conocimiento lo más exacto posible de cómo están utilizando los tribunales dichos principios, es preferible una ciencia jurídica dedicada a dar cuenta asépticamente de cómo están decidiendo los tribunales y a describir el derecho vigente. Cosa diferente es que alguien piense que es mejor un derecho compuesto eminentemente por principios y, además, que la dogmática jurídica debe dedicarse a establecer cuál es el contenido del derecho según los principios del ordenamiento, siendo este último aquél que debería aplicar los tribunales. Pero hay que subrayar que de la primera tesis no se sigue la segunda. Para que la segunda tesis estuviera justificada habría que añadir algún otro argumento de carácter práctico, como que es positivo o moralmente correcto que los dogmáticos se dediquen a publicar artículos acerca de cuál es la interpretación correcta de dichos principios. 
pregunta práctica no se sigue la superioridad de la aproximación interpretativa (SCHIAVELLO, 2014: 211), ni que la ciencia jurídica deba asumir el punto de vista interno o del participante, ni tampoco que deba intentar modificar la práctica del derecho. Se sigue únicamente que hay que dar razones prácticas para decidir qué tipo de dogmática jurídica cultivar, pero no que la dogmática jurídica deba ser práctica.

Lo que es importante subrayar es que diferentes concepciones o modelos de ciencia jurídica, en los que se asumen diferentes «puntos de vista», persiguen en realidad objetivos de investigación diferentes ${ }^{23}$ : qué dice el derecho según su interpretación convencional, qué debería decir a la luz de sus principios o qué es lo que creen los jueces que dicen. Se trata, me parece, de preguntas y objetivos de investigación diferentes, tradicionalmente agrupados bajo etiquetas como «doctrina», «ciencia del derecho»o «dogmática jurídica», pero que implican diversos objetivos de investigación. Pero de aquí de ningún modo, insisto, se sigue que haya que adoptar una posición comprometida con el punto de vista del derecho, sino que hay que decidir, aduciendo razones normativas, si vamos o no vamos a adoptar tal punto de vista. Decir que la ciencia del derecho debe adoptar el punto de vista del participante porque es una disciplina eminentemente práctica es, nuevamente, resolver un problema práctico (qué deben hacer los estudiosos del derecho) mediante un argumento teórico o conceptual (qué es la ciencia jurídica).

Así pues, no podemos decir que la ciencia jurídica es o debe ser una disciplina práctica porque tiene que dar cuenta o asumir el punto de vista interno. En primer lugar, porque afirmar que sólo es posible el conocimiento asumiendo en primera persona el punto de vista del participante lleva a conclusiones claramente absurdas (sólo puede explicar qué es la mafia siendo mafioso, etc.). En segundo lugar, porque la adopción de uno u otro punto de vista dependerá — deberá depender — de cuáles son los objetivos de investigación que deseamos alcanzar. Volveré sobre este último punto más adelante (infra 4.2).

\subsection{El argumento normativo}

Llegamos al segundo argumento, de carácter normativo, de SCHIAVELLO: la ciencia jurídica debe ser una disciplina práctica pues, en otro caso, bien sería irrelevante o bien sería ideológica. Para avanzar sobre este argumento de SCHIAVELLO es necesario recordar qué debemos entender por «disciplina práctica». Como ya sabemos, por «disciplina práctica» podemos entender aquélla que no pretende responder la pregunta sobre cómo es el mundo sino a aquélla sobre cómo debe ser (o qué debemos hacer). Ello, recordemos, en un sentido no meramente técnico o instrumental sino de carácter normativo en sentido fuerte: trata de responder — antes que a la pregunta acerca de cuáles son los medios idóneos para alcanzar un fin, intenta responder- a la pregunta cuáles son los fines que hay que perseguir.

Pues bien, la tesis de que una disciplina de carácter no práctico es irrelevante, como he tratado de explicar en alguna otra ocasión (NÚÑEZ VAQUERO, 2010), es senci-

23 De nuevo, me permito remitir a dos trabajos míos: NúÑEZ VAQUERO, 2013 y 2014. 
llamente errónea. En efecto, del mismo modo que nos resulta de lo más relevante saber qué tiempo va a hacer para decidir si realizamos una excursión al campo durante el fin de semana, igualmente lo es saber cómo están decidiendo los jueces un determinado tipo de controversia, cuáles son las interpretaciones dominantes en la dogmática, o qué valor le atribuye el Tribunal Europeo de Justicia a las directivas comunitarias. Es decir, una serie de datos que responden a la pregunta sobre cómo es el mundo que parecen resultar de lo más relevantes (vid. supra, 2.1). Debemos por tanto descartar esta tesis.

La segunda crítica de SCHIAVELLO sostendría que una disciplina que se presente como neutral es una disciplina ideológica en el sentido de que sería imposible mantener una aproximación neutral a la hora de hacer ciencia jurídica. Se trata, de nuevo, de argumentos ya conocidos sobre los que no es preciso volver. Sin embargo, no me resisto a seguir preguntando qué tiene de no neutral o ideológico presentar cuáles son los criterios de admisión a trámite de los recursos presentados en el Tribunal Constitucional, qué se desprende de la interpretación literal del Código Penal o cuáles son las interpretaciones convencionales o vigentes de los enunciados normativos.

SCHIAVELLO (SCHIAVELLO, 2014: 210) ofrece además un argumento de viejo sabor iusanalítico italiano (SCARPELLI, 1997): si elijo el concepto de derecho, entonces la disciplina no puede ser neutral (y, se podría concluir, menos aún científica). Pero este argumento parece extraño: si un patólogo se concentra en la forma de reproducción del virus del VIH en lugar de en su transmisión, ¿deja por ello de ser su estudio científico, convirtiéndose en ideológico? Lo que es —-mejor dicho, podría ser-ideológico es la elección de qué tipo de investigación queremos llevar a cabo. Ahora bien, del hecho de que yo tenga que tomar una decisión sobre a qué tipo de investigación quiero dedicar mis esfuerzos no se sigue que mi investigación haya dejado de ser neutral o que no puede ser científica.

Es preciso señalar que no estoy sosteniendo que la simple lectura de los enunciados normativos (interpretación literal) permita establecer cuál es el contenido del derecho, entendiendo por este último aquel conjunto de normas que deben ser aplicadas por los tribunales: lo que «auténtica» y «realmente» dice el derecho, y que sería obligatoria para los jueces. Una posición formalista como esta es tan comprometida como la que mantiene la dogmática interpretativa de SCHIAVELLO. Antes bien, lo que sostengo es que es posible presentar qué se desprende (o cuáles soluciones se desprenden) del derecho a la luz de sus principios, según su interpretación convencional o cómo deciden los tribunales ${ }^{24}$, sin incurrir en ningún compromiso práctico ${ }^{25}$. Si luego el dogmático afirma que este es el auténtico derecho que debe ser aplicado por los tribunales es

24 Ello por supuesto no implica que dichas tareas carezcan de dificultades y que en ocasiones, por ejemplo, no esté claro qué se deriva de la interpretación convencional o de la literal, o que no esté claro qué han decidido los tribunales.

25 Imaginemos un estudioso que trata de dar cuenta de cuál ha sido la jurisprudencia de los tribunales en un ordenamiento jurídico en materia de prostitución, tomando todas las razones que han sido empleadas por las diferentes partes, y realizando una proyección respecto a cómo decidirán aquellos mismos tribunales en el futuro. Nuestro hipotético estudioso llega a la conclusión de que los tribunales tendrán una opinión más restrictiva en relación a la prostitución. Pues bien, dicha posición es perfectamente compatible tanto con el rechazo del futuro panorama que se dibuja como con su celebración. Es decir, es posible que el mismo estado de cosas futuro descrito sea considerado, desde un punto de vista ético, como reprobable o como algo que celebrar. Pero si es compatible tanto con una como con la otra posición, entonces es que no existe compromiso 
cosa diferente, y supone el compromiso del estudioso del derecho. Pero, hasta donde alcanza mi conocimiento, presentar o exponer tales cuestiones no implica nada acerca de su aceptación o rechazo, siendo compatible con cualquiera de las dos posiciones. Ello incluso aunque fuera necesario adoptar, a título de hipótesis, el punto de vista del participante ${ }^{26}$.

\section{LA DOGMÁTICA JURÍDICA INTERPRETATIVISTA}

Llegamos así a la última tesis de SCHIAVELLO que analizaré: la ciencia jurídica es y debe ser una disciplina interpretativa. Lo primero que hay que aclarar al respecto es algo que el propio SCHIAVELLO no siempre deja claro; en particular, que hace uso del adjetivo «interpretativo» en relación a la expresión «ciencia jurídica» en dos sentidos diferentes (SCHIAVELLO, 2014: 205). El primero de ellos es para hacer referencia a que el concepto de ciencia jurídica sería un concepto interpretativo, es decir, desde el punto de vista de la meta-teoría de la ciencia jurídica (SCHIAVELLO, 2014: 207). El segundo uso hace referencia a una forma particular o concreta de hacer ciencia jurídica, es decir, como tesis normativa sobre qué tipo de dogmática jurídica es preferible. SCHIAVELLO defiende ambas: aquel de «ciencia jurídica» sería un concepto interpretativo, y la mejor manera de hacer ciencia jurídica sería de forma interpretativa (SCHIAVELLO, 2014: 208).

\section{1. ¿Es interpretativo el concepto de «dogmática jurídica»?}

Abordaré en primer lugar la tesis teórica según la cual el concepto de «dogmática jurídica» es un concepto interpretativo. Pero, ¿qué entiende exactamente SCHIAVELLO por «dogmática jurídica»? Respuesta: «Todos los discursos "de aquéllos que se ocupan de someter a investigación, por motivos 'científicos' el contenido de sectores concretos de un específico ordenamiento jurídico positivo”» (SCHIAVELLO, 2014: 201).

A continuación, es preciso preguntarse qué está entendiendo SCHIAVELLO por «concepto interpretativo». Siguiendo GALLIE a través de DwORKIN, SCHIAVELLO presenta cinco características de los conceptos esencialmente controvertidos, concepto matriz del que derivaría aquel de «concepto interpretativo»: 1) son conceptos que explicitan el valor de una actividad considerada valiosa, y que vinculan dicho valor con dicha actividad; 2) la actividad debe ser compleja y articulada;3) tales conceptos deben tomar en cuenta los diferentes aspectos de dicha actividad; 4) el concepto debe

con ninguna de las dos, ni compromiso en la descripción de la práctica acerca de la calificación que debe recibir la prostitución.

Lo mismo se puede decir respecto si el estudioso tratase de dar cuenta de las posibles soluciones que se podrían derivar con base en los enunciados normativos y los principios del ordenamiento. Nuestro estudioso podría sencillamente dedicarse a dar cuenta de cuáles son las diferentes soluciones que se pueden derivar de aquéllos. Pero ello, nuevamente, no implica que se comprometa con ninguna de las soluciones posibles.

26 Para constatarlo parece suficiente con pedirle a un neoconstitucionalista que intente imaginar qué diría un formalista sobre una parte del derecho, o viceversa. No veo ninguna razón por la que dicho experimento no sea posible y, por el contrario, es algo que los juristas, especialmente los abogados, realizan constantemente, adoptando sencillamente aquella tesis más beneficiosa para sus clientes. 
soportar cambios significativos de la práctica, y 5) su uso presupone la conciencia de que son posibles usos diferentes de tal concepto.

Lo que corresponde en este momento es ver si, efectivamente, el concepto de dogmática jurídica que nos ofrece SCHIAVELLO cumple las características que predica sobre los conceptos interpretativos o esencialmente controvertidos. Pues bien, no está claro cómo el concepto de dogmática de SCHIAVELLO satisface la primera y la última de las cinco propiedades recién presentadas.

Respecto de la primera propiedad (1) —el concepto debe explicitar el valor de la práctica- no se ve cómo el concepto de dogmática jurídica de SCHIAVELLO satisfaría tal condición. A lo sumo, se podría intuir que el concepto de dogmática jurídica explicita el valor de la neutralidad («por razones “científicas”»), pero mucho me temo que no es eso lo que tiene en mente SCHIAVELLO.

Más problemática todavía resulta predicar la quinta propiedad del concepto de dogmática jurídica de SCHIAVELLO: el uso del concepto de ciencia jurídica presupondría la conciencia de que son posibles usos alternativos. Bien visto, parece extraño afirmar que el concepto de «dogmática jurídica» sea interpretativo en este sentido, porque antes que diferentes usos del concepto, parece que estamos frente a diferentes especificaciones, concepciones o formas de hacer dogmática jurídica. En este sentido, el concepto de dogmática jurídica que nos ofrece SCHIAVELLO — recordemos: «Todos los discursos "de aquéllos que se ocupan de someter a investigación, por razones 'científicas' el contenido de concretos sectores de un específico ordenamiento jurídico positivo" » (SCHIAVELLO, 2014: 201) — antes que admitir diferentes usos, es un concepto «paraguas» que sirve para referirse a varias formas (no ya en las que usar el concepto de «dogmática jurídica», sino) en las que hacer ciencia jurídica. Pero ello no implica que se trate de un concepto interpretativo.

Si la expresión «dogmática jurídica», tal como la emplea SCHIAVELLO, permitiera usos diferentes y sirviera para hacer referencia a cosas diferentes, no siendo - como yo creo- un concepto de carácter general que sirve para referirse a actividades diferentes (concepto versus concepciones) pero también para excluir otras, entonces resultaría imposible discutir sobre qué modelo de dogmática jurídica hay que suscribir. No sería, entre otras cosas, posible rechazar un determinado modelo de dogmática jurídica, como hace SCHIAVELLO, sencillamente porque aquello que rechazamos no lo identificaríamos como un ejemplo de dogmática jurídica. Sin embargo, parece que sí disponemos de un concepto general «dogmática jurídica» que permite referirse a actividades heterogéneas: precisamente el concepto que nos presenta SCHIAVELLO es un excelente ejemplo de ello. Si la discusión acerca de qué modelo de dogmática jurídica es deseable, y no veo por qué no lo sería, entonces parece condición de dicha discusión que tengamos un concepto que nos permita identificar ciertas cosas como ejemplos de dogmática.

Tiene razón SCHIAVELLO al lamentarse de que la forma de entender la ciencia jurídica del iuspositivismo analítico italiano ha sido reductiva, pero ello no justifica convertir el concepto de ciencia jurídica en un concepto interpretativo. Si lo que queremos es un concepto de ciencia jurídica que nos sirva para delimitar el marco de aquellas investigaciones que se preguntan sobre qué hacen, qué pueden hacer, o qué deben 
hacer quienes se ocupan de analizar el contenido del derecho, se necesita un concepto de «dogmática jurídica» más articulado y complejo, como afirma el propio SCHIAVELLO (SCHIAVELLO, 2014: 203). Pero, insisto, ello de ningún modo permite concluir que aquel de «dogmática jurídica» sea, o deba ser entendido como, un concepto interpretativo.

\subsection{Sobre la (no) conexión entre método dogmático y concepto de derecho}

Corresponde ahora someter a análisis la tesis de SCHIAVELLO según la cual la mejor forma de hacer dogmática jurídica es aquella interpretativa, es decir, el mejor modelo de dogmática jurídica es aquél que concibe el derecho como integridad.

Para abordar la cuestión, lo que hay que hacer es aclarar qué relación subsiste entre ciencia jurídica y concepto de derecho. Ello porque el propio SCHIAVELLO sostiene que hay que hacer ciencia jurídica interpretativa porque aquél de «derecho» sería un concepto interpretativo. A decir verdad, la relación que SCHIAVELLO establece entre ambas cosas no es del todo clara, básicamente porque afirma no querer profundizar en dicho concepto de derecho (SCHIAVELlO, 2014: 205). Lo que creo que sí se puede afirmar es que SCHIAVELLO defiende que la dogmática jurídica debe ser interpretativa justamente porque el derecho es, o debe ser entendido como, integridad. Es decir, como un concepto interpretativo y/o como una práctica interpretativa.

Aquí no voy a analizar el concepto de derecho como integridad o que implica el giro interpretativo en el sentido aclarado por SCHIAVELLO (SCHIAVELLO, 2014: 203 205). Antes bien, lo que haré será analizar, desde el punto de vista de la meta-teoría de la ciencia jurídica, cómo aborda SCHIAVELLO la cuestión, es decir, cómo justifica su elección por un determinado modelo de ciencia jurídica. En este sentido, la crítica que dirigiré contra SCHIAVELLO se podría dirigir también contra cualquier otro modelo de ciencia o dogmática jurídica que sea defendido o justificado mediante una estrategia argumentativa similar a la empleada por SCHIAVELLO: una que haga depender el modelo de ciencia jurídica de un determinado concepto de derecho. Por ello, no resulta necesario detenerse en el concepto interpretativo de derecho.

En efecto, tradicionalmente en el campo de la teoría de la ciencia jurídica se ha venido haciendo depender el modelo de ciencia jurídica de un determinado concepto de derecho. También aquí es el caso: para ScHIAVELlo la dogmática jurídica debe ser de carácter interpretativo precisamente porque aquél de derecho es un concepto interpretativo. Es decir, se hace depender el modelo o concepción de ciencia jurídica que se debe adoptar de una definición del concepto de derecho. Esta última idea es precisamente la que ha llevado a muchos autores a afirmar que el método depende del objeto de estudio.

Sin embargo, ello no parece una buena idea. Para entender la razón, lo primero que hay que señalar es que un mismo objeto de estudio admite muy diferentes formas de estudiarlo. Frecuentemente se afirma que el método depende del objeto porque se presupone que hay algunas características del objeto que determinan cómo tenemos que estudiarlo. Ahora bien, los objetos tienen infinitas características: pueden ser mirados desde diferentes puntos de vista, siendo el observador el que determina las 
características relevantes. Ninguna de dichas propiedades tiene algún tipo de preferencia sobre el resto, sino que dicha preferencia es establecida precisamente por quienes analizan o estudian el objeto.

Cuando definimos el derecho, o cualquier otra cosa, lo que hacemos es considerar como relevantes ciertos aspectos o propiedades, descartando todas las demás. Pero para poder seleccionar tales propiedades relevantes, necesitamos una tesis de relevancia. El problema es que la literatura teórico-jurídica ni siquiera se pone de acuerdo acerca de cuáles son los criterios para establecer cuáles son las propiedades que debería cumplir nuestra mejor definición del concepto de derecho (tesis de relevancia).

Sospecho que el problema tiene su origen en una mala teoría de los conceptos; en concreto, en la idea de que los conceptos tienen un poder explicativo autónomo más allá de las teorías en las que ellos se inscriben (o que podemos elegir entre diferentes conceptos independientemente del marco teórico en el que se inscriben). Sin embargo, los conceptos no son entidades que flotan en el mundo abstracto ni tienen autonomía explicativa. Los conceptos, aunque no son los únicos, son los instrumentos que forman o constituyen las teorías y nuestras empresas prácticas (en sentido amplio ${ }^{27}$ ), y carecen de utilidad o relevancia más allá de aquéllas. Desde este punto de vista, no podemos preguntarnos cuál es el mejor concepto de derecho si no respondemos antes a la pregunta de para qué queremos un concepto de derecho ${ }^{28}$. En este sentido, si bien un buen concepto de derecho (o de cualquier otra cosa) debe cumplir con diferentes requisitos — no estar basado en asunciones falsas, no ser innecesariamente complejo, etc.—, tal concepto debe ser sobre todo útil en el marco teórico en el que se inserta. Es decir, dentro de una teoría explicativa o normativa que pretende describir el mundo o realizar propuestas para cambiarlo, deberemos adoptar uno u otro concepto de «derecho».

Por tanto, no podemos decir que el objeto determina el método, o que por el hecho de ser interpretativo el concepto de «derecho» debe serlo también la ciencia jurídica. Antes bien, para determinar qué concepto de derecho emplear, se debe decidir previamente qué tipo de investigación se desea llevar a cabo. Para justificar tanto el concepto de «derecho» como el método de estudio a emplear, lo que tengo argumentar es qué objetivos de investigación voy a perseguir, con qué método, y por qué sería valioso perseguir tales objetivos de investigación. En caso contrario, estaríamos resolviendo un problema práctico — qué tipo de dogmática deberíamos desarrollarmediante una definición, lo que no parece muy buena idea. Por tanto, SCHIAVELLO está poniendo la carreta delante de los bueyes.

27 Es decir, incluyendo tanto aquella empresa en el que tratamos de establecer, mediante un razonamiento del tipo medios-fines, los instrumentos necesarios para alcanzar un determinado objeto, como aquélla en la que nos preguntamos acerca de cuáles son los fines que debemos perseguir (o qué debemos hacer en un sentido ético-político o moral).

28 Afirmar que el mejor concepto de derecho para la dogmática es un concepto, en términos dworkinianos, doctrinal —como sugirió uno de los evaluadores anónimos- tiene el problema de que presupone precisamente la respuesta a la pregunta sobre cuáles deben ser los objetivos de la ciencia jurídica. A menos, claro está, que se considere que hay múltiples conceptos doctrinales de derecho pero, en ese caso, entonces se vuelve a reproducir el problema acerca de cuál de todos ellos hay que seleccionar: aquél según el cual son verdaderas las proposiciones normativas que reflejan la intención del legislador, las proposiciones normativas que reflejan el valor de la integridad, las proposiciones normativas que dicen cómo decidirán los jueces, etc. Pero, obviamente, para elegir entre aquéllos tengo que decidir primero qué tipo de investigación quiero llevar a cabo. 
No obstante, se podría sostener que, al tratarse el derecho de una práctica de naturaleza interpretativa, entonces la dogmática jurídica debe ser necesariamente interpretativa ${ }^{29}$. Creo que hay que deshacerse inmediatamente de razonamientos como el anterior que apelan a la supuesta naturaleza del objeto de estudio. Dicho de manera clara y directa: no existe nada en el mundo como la «naturaleza de las cosas», y no en este caso una supuesta «naturaleza» del derecho. Lo único que existe, desde este punto de vista, son atribuciones de supuestas naturalezas por parte de quien analiza el objeto de estudio, pero las «naturalezas» $\mathrm{o}$ «preferencias» de determinadas propiedades son el resultado de elecciones epistémicas de quien lo estudia, no una propiedad ontológica ${ }^{30}$.

Pero, incluso aunque el derecho tuviera una naturaleza, y esta fuera interpretativa o justificativa (o que el mejor concepto de derecho fuese el interpretativo), sería necesario argumentar y justificar por qué la ciencia jurídica debe participar en la práctica jurídica, y no permanecer al margen de aquélla. Es más, incluso aunque se admitiera que el derecho se sostiene desde valores morales, ello no implica que la dogmática jurídica deba entra en el juego de determinar cómo deben decidir los tribunales los ca$\operatorname{sos}^{31}$ : podría, insisto, dedicarse a mostrar las respuestas posibles sin elegir ninguna de ellas como la respuesta realmente correcta, evaluando por ejemplo las consecuencias prácticas de cada una de ellas.

Por muy obvio que les parezca a algunos, la interpretativa es sólo una de las alternativas y, por tanto, es necesario justificarla. Hay, dicho de otro modo, que justificar normativamente por qué una dogmática interpretativa sería mejor para el mundo: porque hace que los jueces decidan mejor, porque hace que tengamos una comunidad jurídica más democrática, porque es un sano ejercicio de libertad de expresión, etc. Sostener que el derecho le suministra los objetivos, valores y métodos a la ciencia jurídica - a menos que se demuestre que hay una norma en el ordenamiento que obliga a los dogmáticos a elegir un determinado método u objetivo de investigación (que, hasta donde llega mi conocimiento, no está presente en ningún ordenamiento)— parece una afirmación carente de justificación.

\section{UNA CRÍTICA FINAL AL MODELO INTERPRETATIVO DE DOGMÁTICA JURÍDICA}

Quiero finalizar este comentario con una crítica, por decirlo de algún modo, más directa al modelo de ciencia jurídica interpretativa. Concuerdo con SCHIAVELLO en que el modelo triunfante de dogmática jurídica ha sido aquel del jurista creador, tanto en el plano de la teoría de la ciencia jurídica como entre los propios estudiosos del

29 Este argumento, de manera ligeramente diferente a cómo lo presenta SCHIAVELLO, me fue planteado por uno de los evaluadores anónimos de la versión anterior de este texto.

30 En el mejor de los casos, existen creencias de los participantes en una práctica acerca de la naturaleza de la práctica misma, pero nada garantiza que dicha creencia sea verdadera.

31 Negar esta tesis sería como afirmar que no puedo hacer estudios de ciencia política porque la política es una actividad regida esencialmente por valores éticos. Dicho nuevamente mediante una analogía: es lo mismo que si pensáramos que hay que estudiar las religiones presuponiendo la existencia de Dios porque la práctica religiosa presupone la existencia de Dios. 
derecho. Lo que temo, sin embargo, es que su éxito no haya sido tan positivo como SCHIAVELLO cree, por dos razones. La primera se refiere a la legitimidad moral o éticopolítica de este modelo de dogmática jurídica. La segunda tiene que ver con la relación entre las propuestas que desde esta dogmática se llevan a cabo y la realidad en la que aquéllas se inscriben.

\subsection{Sobre la (falta de) legitimidad de la dogmática interpretativa}

Para entender la primera crítica, en primer lugar, hay que aclarar que, cuando se asume o se propone un modelo de dogmática jurídica como el interpretativo, no se trata únicamente de que no nos estemos limitando a describir cuál es el contenido del derecho, como lo haría el biólogo que describe una célula. No es únicamente, por tanto, que los estudiosos busquen una respuesta que ya está en el derecho, y que sólo debería ser descubierta a través de un procedimiento más o menos escrupuloso.

Lo que este modelo interpretativo de ciencia jurídica invita a hacer a los estudiosos del derecho es a construir ellos mismos el derecho, mediante un procedimiento que sólo está delineado en términos generales ${ }^{32}$ —la llamada teoría estándar de la argumentación- y que le permite un gran margen de creación y discrecionalidad. Dicho ámbito de creación discrecional debe ser cubierto no únicamente con los principios y valores del ordenamiento, sino con la que cada autor considere justificadamente que es la mejor interpretación posible de aquéllos. En otro caso, si no fuera necesario que el dogmático aportara algo propio a dicha tarea, si únicamente se requirieran los principios y valores del ordenamiento, la tarea del estudioso del derecho sería más similar a la del arqueólogo que excava hasta encontrar la respuesta que a la del constructor de buenas respuestas que SCHIAVELLO nos propone. O, dicho en términos más precisos, si los principios y valores ya nos dieran la respuesta jurídicamente correcta, la tarea sería puramente descriptiva, lo que no estaría dispuesto a admitir SCHIAVELLO. Por tanto, el papel de la dogmática jurídica interpretativa de SCHIAVELLO tiene una función creadora, no tanto porque invente respuestas ex novo (o introduzca normas que encuentran fundamento evidente en los textos normativos, cosa que también hace), sino, sobre todo, porque se dedica a ordenar y a jerarquizar los materiales jurídicos. Dichas ordenaciones y jerarquizaciones no están regidas por normas jurídicas ni por un método preciso (carente de normas vagas, antinomias y de lagunas de segundo orden), sino que están regidas, al menos en parte, por las preferencias ético-políticas de los estudiosos del derecho.

Pues bien, más allá de la debatida cuestión acerca de si nuestras discusiones prácticas tienen o no sentido, lo que parece poco discutible es que no existen expertos morales (tampoco estúpidos). Es decir, no hay ningún tipo de conocimiento que haga que nuestras decisiones morales o ético-políticas sean mejores desde un punto de vista sustantivo, es decir, de su contenido. Se podrá, desde luego, estar frente a decisiones

32 Delineado únicamente en términos generales porque prevé un gran número de instrumentos, muy bien perfilados algunos, pero carece de meta-normas sobre la preferencia del uso de aquéllos. Dicho con un ejemplo, no hay reglas para saber si debemos emplear, frente a un caso difícil, el razonamiento a contrario o por analogía. 
mejor y peor argumentadas, pero ningún tipo de conocimiento permite decir que el contenido de una decisión es mejor que otra por razón de ningún tipo de conocimiento experto $^{33}$. Ni tampoco una respuesta mejor desde el punto de vista formal garantiza una mayor calidad de su contenido: una decisión perfectamente argumentada no tiene por qué ser, desde el punto de vista de su contenido, mejor que otra que carece de argumentación, ni viceversa.

Estando así las cosas, entonces hay que preguntarse para qué queremos una dogmática que busque orientar las decisiones judiciales. Si no podemos garantizar que las respuestas provenientes de la dogmática jurídica sean mejores respuestas desde el punto de su contenido moral o ético político: ¿para qué queremos una dogmática que oriente, mediante juicios ético-políticos, las decisiones de los jueces?

La cuestión no es sólo que este tipo de dogmática pueda carecer de legitimidad o de justificación suficiente para proponer soluciones sobre las cuales no hay razones para que sean mejores desde un punto de vista sustantivo. En el peor de los casos, se trataría sólo de un discurso bienintencionado que no genera ningún daño. El problema es que sí genera un daño. La dogmática, como bien afirma RuIz MiguEL (RUIZ MigueL, 2012), está revestida de una legitimidad social que hace que sus propuestas de construcción jurídica — no la simple descripción del derecho-cuenten como argumentos de autoridad. El resultado es que, voluntaria o involuntariamente, los dogmáticos interpretativos se aprovechan de su prestigio social para establecer cómo deben decidir los jueces o qué debemos hacerle decir a los textos jurídicos. Pero no hay razón por la que los jueces debieran hacer más caso a estos dogmáticos que a cualquier otro ciudadano informado cuando se trata de la construcción del derecho. Se trata, en resumidas cuentas, de una actividad de legislación subrogada. Sin embargo, debido a ese prestigio social, lo cierto es que las opiniones de los dogmáticos tienen una relevancia fundamental en la creación del derecho, sin que haya ninguna justificación evidente para ello.

Pero las cosas son, si cabe, un poco peores todavía. Una de las principales características de este tipo de dogmática es que es perfectamente capaz de derivar respuestas - por cierto, muchas veces contradictorias, partiendo supuestamente de los mismos puntos de inicio- para cualquier problema práctico. Adoptando un método que tiene claras similitudes con la filosofía moral subyacente al iusnaturalismo racionalista, ningún problema práctico escapa a su ámbito de conocimiento.

Esto podrá ser considerado incluso una virtud por parte de algunos autores, SCHIAVELLO incluido. Sin embargo, resulta de lo más discutible desde el punto de vista democrático. El problema es que no se dice que estas son sencillamente las opiniones de los dogmáticos, sino que se atribuyen al derecho tales opiniones, diciendo que es lo que el derecho nos requiere (y es debido hacer) o, en el mejor de los casos, lo que el derecho debería requerirnos de acuerdo a sus principios (y debemos ser coherentes). Ahora bien, si no existen expertos morales y las propuestas de solución provenientes de la dogmática jurídica no garantizan una mayor calidad (desde el punto de vista de su contenido), entonces tal vez se esté hurtando a las mayorías (legas en derecho) la decisión sobre problemas a los que este tipo de dogmática se estaría encargando de

\footnotetext{
33 En caso contrario, nos veríamos obligados a revisar instituciones como la democracia.
} 
dar respuesta por su cuenta. Nada escapa a una dogmática expansionista como esta que considera el derecho como integridad: ni la más nimia decisión hace falta que sea dejada al legislador democrático ${ }^{34}$.

\subsection{Sobre la (falta de) conexión con el conocimiento científico de la realidad}

La segunda crítica al modelo interpretativo, o argumentativo, es similar a la que le dirigió JHERING a la dogmática conceptualista (JHERING, 1987). Es decir, del mismo modo que JHERING criticó a la dogmática conceptualista por haber perdido el contacto con la realidad en la que se aplicaban sus construcciones, algo parecido se puede decir de la dogmática interpretativa. A saber: encerrado en su torre de marfil, el dogmático interpretativo busca, incansable, la mejor respuesta posible según la mejor interpretación de los principios y valores constitucionales, sin preocuparse de qué es lo que sucede fuera de sus puertas. Como bien dijo una vez un defensor del modelo interpretativo, buscar la mejor respuesta es intentar hacer cuadrar todas las piezas, como hacer un crucigrama (PÉREz BERMEJO, 2009, 41 y ss.).

El problema de este tipo de dogmática es que el conocimiento que tiene de la realidad, del lugar en el que se insertarán sus propuestas de solución, es sólo a través de la mirilla de su puerta: un pequeño agujero con cristal curvo que deforma la realidad. En lugar de salir a buscar el mejor conocimiento científico sobre la sociedad, la dogmática interpretativa se contenta con un conocimiento sólo de sentido común de la realidad (SCHIAVELLO, 2014: 195).

Si pese a todo se sigue considerando que la dogmática jurídica debe orientar las decisiones judiciales, en lugar de desairar a autores como FRANK o LUNDSTEDT, tal vez sería bueno volver sobre ellos para pensar en una dogmática más atenta a las consecuencias de las decisiones jurídicas que trata de orientar, capaz de insertar en el razonamiento jurídico el mejor conocimiento social disponible. Mucho me temo que esta dogmática interpretativa, tan honorablemente preocupada por los principios, ha dejado de lado el conocimiento científico de la realidad, conformándose con un conocimiento de sentido común sobre aquélla. Pero una dogmática que no tenga un conocimiento científico de la realidad en la que se inscriben sus propuestas será una dogmática ineficiente o directamente inútil.

Cabría preguntarse, ¿por qué debería la dogmática emplear el mejor conocimiento disponible en la dogmática jurídica? Si se supone que el derecho es un instrumento para la gestión de los conflictos de una sociedad, entonces sólo un conocimiento de esa misma realidad social podrá sugerir los medios idóneos para alcanzar determinados objetivos. Un conocimiento de la sociedad puramente de sentido común no permite adoptar los instrumentos idóneos para alcanzar objetivos porque no se conocen los mecanismos e instrumentos que permiten el cambio o la conservación de una parte de la sociedad: únicamente nos ofrece, con suerte, algunas buenas intuiciones.

34 Este es precisamente el estilo de argumentación que también han adoptado los jueces de muchos Tribunales constitucionales, siendo auténticas aspiradoras de competencias, que ha llevado, al menos en parte, a la crisis de los sistemas de justicia constitucional. 
En un mundo en plena crisis en el que los cambios sociales se suceden a una velocidad inaudita, tal vez sería mejor recuperar el estilo de dogmática basada en un conocimiento científico de la realidad, al estilo de FRANK o LUNDSTEDT, pero también de juristas como BrANDEIS o el Grand Style del que hablaba LLEWELLYN (LLEWELLYN, 1953). La torre de marfil en la que se han encerrado buena parte de los estudiosos del derecho, alentados por esta dogmática interpretativa, es tan alta que su visión de la realidad es cada vez más borrosa, y sus propuestas cada vez más inútiles.

\section{BIBLIOGRAFÍA}

ATIENZA, M., 1986: «Sobre la jurisprudencia como técnica social», Doxa, 3, 279-311.

— 2014: «La dogmática jurídica como tecno-praxis», en Á. NúñEz VAquero, Modelando la ciencia jurídica, Lima: Palestra, 13-51.

BoвBIO, N., 1997: Autobiografia, Roma-Bari: Laterza.

- 2007: «Diritto e scienze sociali», en Dalla stuttura alla funzione, Roma-Bari: Laterza, 31-47.

- 2011: Saggi sulla scienza giuridica, Torino: Giappichelli.

Broncano, F., 2000: Mundos artificiales, México: Paidós.

BulYGIN, E., 1991: «Normas, proposiciones normativas y enunciados jurídicos», en C. ALCHOURRÓN y E. BULYGIN, Análisis lógico y derecho, Madrid: CEPC, 169-193.

Frank, J., 2009: Law and the Modern Mind, New Brunswick: Transaction Publishers.

GUASTINI, R., 2014: «El realismo jurídico redefinido», en Á. NÚÑEZ VAQUeRO, Modelando la ciencia jurídica, Lima: Palestra, 87-114.

JHERING, R., 1987: Bromas y veras en la ciencia jurídica, Madrid: Civitas.

LLEWELLYN, K., 1953: Belleza y estilo en el derecho, Barcelona: Bosch.

LundSTEDT, V., 2014: «La jurisprudencia como ciencia», en Á. NúÑEz VAquero, Modelando la ciencia jurídica, Lima: Palestra, 161-202.

NinO, C. S., 1995: Algunos modelos metodológicos de «ciencia jurídica», México: Fontamara.

NÚÑEZ VAQUERO, Á., 2010: «Algunos comentarios sobre un debate entre constitucionalistas y realistas», en Analisi e Diritto, 319-331.

- 2013: «Five Models of Legal Science», Revus, 2-23.

— 2014: «Ciencia jurídica: un mapa conceptual», en Á. NúÑEZ VAQUERO, Modelando la ciencia jurídica, Lima: Palestra, 13-51.

Pérez Bermejo, J. M., 2009: «Normas jurídicas, conflictos y derrotas: entre reglas ad hoc y sub specie aeternitatis», Analisi e Diritto, 11-60.

Ruiz Miguel, A, 2012: «Dogmática jurídica ¿ciencia o técnica?», en A. CABAnILlas SánCHEZ, (ed.), Estudios en homenaje al profesor Luis Diez-Picazo, vol. 4, Madrid: Civitas, 5649-5680.

SCARPELLI, U., 1997: Cos'è il positivismo giuridico, Napoli: Edizioni Scientifiche Italiane.

SCHIAVELlo, A., 2014: «Algunos argumento a favor de una ciencia jurídica interpretativa», Doxa, 37, 193-217.

Summers, R., 1971: «The Technique Element in Law», California Law Review, 59, 3, $733-751$. 